\title{
General Medicine without Time
}

Jose Luis Turabian

Family and Community Medicine, Health Center Santa Maria de Benquerencia, Regional Health Service of Castilla la Mancha (SESCAM), Toledo, Spain

${ }^{*}$ Corresponding author: Jose Luis Turabian, Family and Community Medicine, Health Center Santa Maria de Benquerencia, Regional Health Service of Castilla la Mancha (SESCAM), Toledo, Spain, Tel: 34925154508; E-mail: jturabianf@hotmail.com

Received date: July 27, 2018; Accepted date: August 01, 2018; Published date: August 06, 2018

Copyright: @ 2018 Turabian JL, This is an open-access article distributed under the terms of the Creative Commons Attribution License, which permits unrestricted use, distribution, and reproduction in any medium, provided the original author and source are credited.

\begin{abstract}
Access to medical knowledge in relation to the main problems that constitute knowledge and work of the doctor can be done in several complementary ways. One of these roads is historical knowledge. If we study the form and content of medical textbooks at different times we could see how they reflect the dominant medical theory at each time according to the publication dates and so we could detect trends on the concepts of etiology, diagnosis, treatment, etc. of the different health problems. The contemporary debate on the development of science and technology, part of the assumption that science and technology have a linear development but the study of history affirms that the fundamental principles of medicine do not change in spite of scientific, technological or socio-political advances. Our profession has an immutable base of assistance, concern for others and curiosity of being the patient as a person, the axis of medical practice, respect for the autonomy of the patient, meticulous observation, etc. Some of the elements that define the medical being in an immutable and without time or epoch way are: 1-variability and induction; 2-research; 3-biopsicosocial, functional and somatic; 4-diagnosis; 5-healthy and sick: the disease develops as a time of life; 6-the anamnesis is almost everything and the complementary tests are not almost anything; 7-course, prognosis, evolution and context and 8-treatment depends on individual internal and external contexts.
\end{abstract}

Keywords: History of medicine; Philosophy; Medical; Humans; Physician-patient relations; Physicians

\section{Introduction}

One of the problems in trying to describe the great moments in the history of medicine is that the turning points are difficult to pin down. Surprisingly, there have been few transcendental discoveries. In addition, there is no continuous record of these major changes. However, the lack of such systemic registration has had the advantage of excluding the element of mythology and partisanship [1].

Access to medical knowledge in relation to the major issues or problems that constitute the knowledge and work of the doctor such as the morphological problem, physiological, pathological, therapeutic, health, and social can be done by several complementary and nonincompatible ways: The reflective knowledge (or) insight theoretical, statistical knowledge, experimental knowledge, speculative knowledge (which deals with the investigation of reality by accepting a priori general principles; It is the intellectual activity that allows the resolution dialectic of contradictions in a higher order unit) and last but not least, the historical knowledge [2-4].

So you have to know the history to be able to understand reality. If we study the form and content of medical textbooks at different times we could see how they reflect the dominant medical theory at each moment according to the publication dates and so we could detect trends on the concepts of aetiology, diagnosis, treatment, etc. of the different health problems. In this way it could be detected if there are certain tendencies such as the emphasis towards the biological or towards the bio-psychosocial or the transformation of the clinic. Of course, the description of diseases in ancient books such as in Hippocrates has changed or has been altered in modern times transformed by scientific advances, diet, hygiene, medicines, etc.
However, just as for example, the history of religion does not have much to do with religious experience or in the same sense art history is not connected with artistic experience; the history of medicine can have not much with experience of medical practice. In order to try to understand something of a certain period of medicine and its circumstances we must realize that it is different from the enthusiasm that draws medical professionals with respect to certain medical advances in each era.

As for example, it may seem that the Greek art is replaced by the Roman art and this by Gothic, and then by the Renaissance, etc., and yet, the more productive an artist or an era has been his works remain without an era that limits to they: the human figures in stone representing idols of the Greek civilization, correspond to abstract forms of the cubist sculpture of the $20^{\text {th }}$ century. The bronze statues of the Roman era resemble contemporary impressionist sculptures, the prehistoric vases of the Stone Age about 2000 BC with its unusual shape and ornamentation. The points of contact with the objectives of applied modern art, the Egyptian wall-painting, about 1900 BC they look like paintings by Henri Matisse of the $20^{\text {th }}$ century, some mosaics from the Roman era about 1160, they look like Van Gogh's portraits, certain Japanese drawings about 1800 suggest the humour of George Grosz, some landscapes by Francisco de Goya about 1815 anticipate the symbolist's illustrations Alfred Kubin in 1900, some vessels of the Chimu Culture of Peru about 900 AD, look like modern sculptures, some Yoruba masks from Upper Guinea have similar looks to European Gothic cathedrals from 1300 etc. [5].

The contemporary debate about the development of science and technology is part of the assumption that science and technology have a linear development, a universal path in which the only significant distinction is that which is given between one concept more advanced or a more advanced technology and another less advanced or delayed 
Page 2 of 4

concept or technology along said historical continuum. This is an evolutionary conception as a conceptual and technological Darwinism of survival of the most appropriate, efficient and most productive concepts and technologies. This linear vision of the conceptual development of medicine is usually accompanied by a deterministic conception in which scientific and technological development is conceived as a universal independent variable that is transformed societies and cultures in their inexorable development. In this linear vision of development, the physician must transform and adapt the ancient culture so that it becomes compatible with modern activities and institutions. The concepts and relationships of an "old" medicine must give way little by little to new concepts, technologies and evaluation systems $[6,7]$.

\section{Discussion}

August Comte, philosopher of the $19^{\text {th }}$ century divided the periods of history (ancient, medieval, renaissance, modern, illustration, etc.) into three states: Theological (fictitious), Metaphysical (abstract) and Scientific (positivist). This division is convenient because it not only demonstrates the timelessness and transcendence of medicine but it also makes it obvious that the cyclical nature of medical interests continues even today to offer a theological, metaphysical and scientific approach to the problems of health care [1].

The pressures to which medicine has been subjected for the past 2,500 years have been successfully navigated back to the foundational values of medicine which are both timeless and immutable. We must support these principles and defend the description of the Ideal doctor, these principles should guide the way medical care is delivered as they are rooted in the commitment that medicine has made to society since the Hippocratic Oath was written [8].

In this sense reading the scientific texts of the past will sometimes lead to the memory the principles and concepts forgotten. Oddly enough, men often forget important scientific findings even if they have left written evidence and when this happens, an attentive search of the texts of the past will allow conquering the dignity of "inventor" with little cost. Today when the bibliography of the works that appear in scientific journals usually only refers to the three or five years prior to the publication date, I am sure that a thorough examination of the collections of European and American journals published between 1850 and 1950 will lead to "discover" facts and ideas that have since disappeared from the memory of doctors $[9,10]$.

The conceptual and practical vision of those great themes or problems of medicine analyzed in the light of the history of medicine.
It shows us that they are cyclically found in distant times and often still appear or re-appear in our days with a modern sense. The famous medical hygienist and historian Henry Sigerist said about it "medicine is the study and application of biology in a structure of humanity that is at the same time historical, social, economic and cultural [11-15]. Therefore in reality the hypothesis of linear historical progress is not met with the elimination of certain ideas and concepts and the appearance of new ones. On the contrary in medicine, despite its accelerated technological and biomedical development there are changes and concepts of past epochs which re-appear repeatedly in each present time.

In this context, based on Richard Siebeck (1883-1965) [16] who along with Ludolf von Krehl and Viktor von Waizsacker were the pillars of the Heidelberg anthropological school (and who gave special importance to the biography of the patient, his pathographic evolution and its historicity: "The patient does not have a disease but he does his illness") to know the social aspect (relational), the ethical aspect (their resignations, duties, values and principles) and above all the spiritualreligious aspect (the meaning that for the patient has life, death, God) we are going to show some of those medical concepts that seem not to have a time but just as they appear at the beginning of the century $\mathrm{XX}$, re-appear at the beginning of the $21^{\text {st }}$ century [16].

So can we found invariable elements in medicine? Of course yes. The study of history affirms that the fundamental principles of medicine do not change in spite of scientific, technological or sociopolitical advances. Our profession has an immutable base in attendance concern for others and curiosity. From the primitive healers doctors have always been there to take care of patients. Although we cannot heal our promise to the patient is to serve him tirelessly to be curious and enterprising in the search for new forms of help and never abandon him. These commitments will define our profession forever and for this reason it is important that we study its history [17].

Not everything is change, some things are immutable and they are still similar today as in the times of Osler. The patient as a person and as the axis of medical practice, the respect for the patient's autonomy, the learning in medical rotations, the importance of hard work, meticulous observation, continuous education and the application of theory and knowledge to the patients, the attitude towards work, the enjoyment of daily activities, and relationships with colleagues are some elements what define the medical being in an immutable timeless way [18-23].

Some of these concepts of medicine without epoch are (Table 1, Figure 1):

\begin{tabular}{|l|l|}
\hline Principles of Medicine Without EPOCH & Concepts \\
\hline 1-Variability, Induction & $\begin{array}{l}\text { No clinical history is totally similar to another; no clinical picture completely coincides with the description that is } \\
\text { made in the manuals. General concepts must be induced from the meaning of each particular case }\end{array}$ \\
\hline 2-Research & Depth has suffered at the expense of the extension \\
\hline 3-Biopsicosocial, Functional and Somatic & $\begin{array}{l}\text { The somatic and the psychic do not let themselves be separated. The circle that leads from the functional to the } \\
\text { organic and from here back to the functional is of the greatest general importance }\end{array}$ \\
\hline 4-Diagnosis & $\begin{array}{l}\text { Being sick is something very different from having discomfort. With the diagnosis, the personality and its situation } \\
\text { are attacked, which essentially affects the organ }\end{array}$ \\
\hline $\begin{array}{l}\text { 5-Healthy and Sick; The disease develops like a } \\
\text { time of life }\end{array}$ & $\begin{array}{l}\text { The multiple relationships and links in human life must be known, if you want to understand the sick, if you want to } \\
\text { delimit between sick and healthy and if you want to establish these limits }\end{array}$ \\
\hline
\end{tabular}




\begin{tabular}{|l|l|}
\hline $\begin{array}{l}\text { 6-The anamnesis is almost everything and } \\
\text { complementary proofs are almost nothing }\end{array}$ & $\begin{array}{l}\text { Despite the importance of technological diagnosis, it is essential to take care of its limits. It allows recognizing the } \\
\text { disease but does not allow knowing the patient }\end{array}$ \\
\hline 7-Course, Prognosis, Evolution and Context & $\begin{array}{l}\text { Clinical disease is the history of a lifetime. Disease depends on the course and prognosis of the personality and } \\
\text { its situation. Each patient does not "have" only "his illness"; He himself and his destiny "form" it. }\end{array}$ \\
\hline $\begin{array}{l}\text { 8-The treatment depends on the individual internal } \\
\text { and external contexts }\end{array}$ & $\begin{array}{l}\text { The possibilities of therapy have limits that are marked by the influence of the position and character of the patient } \\
\text { and their social, professional and financial situation }\end{array}$ \\
\hline
\end{tabular}

Table 1: Some concepts of medicines without EPOCH.

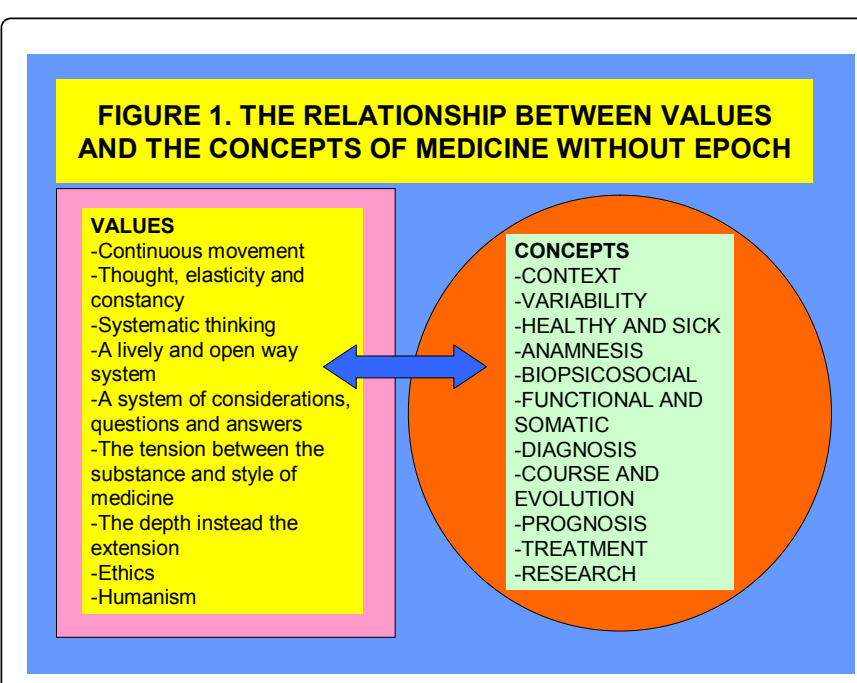

Figure 1: The relationship between values and the concepts of medicine without $\mathrm{EPOCH}$.

\section{Variability, induction}

Like everything living being, medicine develops in continuous movement as well as with regard to the variability of its conceptions, interpretations and needs of the moment as in every encounter between doctor and patient. The doctor is finding new problems every time; no clinical history is totally similar to another, no clinical picture completely coincides with the description that is made in the manuals. The content of medicine is unlimited and moves continuously only based on a series of fundamental ideas are able to combine thought, elasticity and constancy. The fundamental must have been elaborated clearly and severely but not in the form of a rigid "system" but in a lively and open way. But that is why a systematic thought is necessary. We are not going to search for a system of nosological entities but rather a system of considerations, questions and answers that allow each patient to establish a judgment and treatment. Practical work should engender the fundamental ideas; the general concepts must be induced from the meaning of each particular case.

\section{Research}

Medicine is "up and running" and so it has also happened in the field of clinical and experimental research. Many important things were published in the last years but also many other inconsequential ones. It seems as if the depth has suffered at the expense of the extension. Who is able to know today the immeasurable bibliography even if it is only of a limited field? Who can be guided in the labyrinth of the innumerable praises of new medicines?

\section{Bio-psychosocial, functional and somatic}

The causes of illness are often related with increased tension, internal or external restlessness, a very irregular or hectic way of living, critical situations in professional life etc... Is it a somatic or psychic origin? Is it the inside (tension) what induces the outside (an irregular life) or is it the outside (irregular and hasty food, lack of rest and relaxation) that induces the inside? The somatic and the psychic do not let themselves be separated. They constitute a vital unit, although it seems sometime to us that a part is more important aspect than the other. Functional disturbance leads to organic lesion, the organic lesion to the functional disturbance. This circle that leads from the functional to the organic and from here back to the functional is of the greatest general importance. At the same time we have to observe something else: The tendency to functional disturbance and organic injury are equally constitutional, since constitution is always function and organicity at the same time. The more frequent and serious the functional disturbances, the more you can count on an organic defect.

\section{Diagnosis}

Being sick is something very different from having discomfort. Each degree of severity of the disease has its special vital value. It is not only determined by the pathology found in the examination but by the general state, and by the position of the personality. Do not underestimate what this means for the formation and development of the disease, both in the psychic and in the somatic sphere. With the diagnosis, the personality and its situation are attacked, which essentially affects the organ.

\section{Healthy and sick: The disease develops like a time of life}

The "healthy" person (which is not a quantitative and biological concept but related to the personality, with its position and situation, environment and community) feels good and strong. The healthier we feel the less attention we pay and the less we know about health. The patient feels the illness; the doctor discovers it or at least accepts it. The patient feels discomfort, feels impeded, bothered and threatened, whether his change from healthy to sick, occurred suddenly or whether the transformation occurred gradually and it was discovered only casually. The multiple relationships and links in human life must be known, if you want to understand the sick, if you want to delimit between sick and healthy and if you want to establish these limits. Not all discomfort, or any deviation in structure and function, or all "bad mood", or any wrong posture or poor performance are "pathological." Where should we set the limit? Health and illness have meaning, a meaning for life, existence, position and performance within the 
Page 4 of 4

community. The disease develops as a time of life, changes or progresses, and always leaves its traces. It is the destiny that man carries within him, that reaches him from the outside. The doctor has to decide between healthy or sick, not for this or another concept but as life offers it.

\section{The anamnesis is almost everything and complementary proofs are almost nothing}

The scope of the anamnesis is very important. It informs us of the dependence of the functional disturbance of internal and external circumstances. Through her we know of the patient's suffering what it means to him, what his being is, and his state in the world. Despite the importance of technological diagnosis (radiological, endoscopic, etc.) it is essential to take care of its limits. This kind of diagnostic allows recognizing the disease but does not allow knowing the patient. The anamnesis allows a judgment about the position of the patient in front of his predisposition to the disease and how they mesh disease state and pathology.

\section{Course, prognosis, evolution and context}

Clinical disease is the history of a lifetime (problems, desires, failures, successes, efforts..., mark exacerbations or improvements...). It shows that disease depends on the course and prognosis of the personality and its situation and it also points out the importance of the treatment established in time-before deep or irreversible structural anomalies are produced. The disease always develops in the course of a life replete with history; it always has multiple roots both internal and external, the same in the somatic as in the psychic sphere and in the personal and social ligaments. Health and illness should not be interpreted only by their biological references but also by their personal references. The transformation from healthy to sick, either unforeseen or very slow is linked to a general commotion derived from the more or less conscious experience of suffering, knowledge of the diagnosis and interpretation of its meaning. How the illness proceeds and what it means for the patient does not depend only on the "disease" but also essentially on the patient himself, on his position and his situation in life. Each patient does not "have" only "his illness"; he himself and his destiny "form" it. A clinical history is at the same time a story of a lifetime.

\section{The treatment depends on the individual internal and external contexts}

The possibilities of therapy have limits that are marked by the influence of the position and character of the patient and their social, professional, and financial situation and are often absolutely decisive in the total interpretation. The therapy is based on the recognition that the best conditions of the cure are born from the calm and balance of disturbed and excited functions. The treatment should also be directed towards the personality posture.

\section{References}

1. Dolan JP, Holmes GR (1984) Some important epochs in medicine. South Med J 77: 1022-1026.

2. Entralgo PP (1978) Historia de la medicina. Salvat (Medical Pocket Library).

3. Russell B (1983) El conocimiento humano. Barcelona: Ediciones Orbis.

4. Hume D (1994) Investigación sobre el conocimiento humano. Barcelona: Altaya.

5. Goldscheider L (1937) Art without Epoch. The Phaidon Press, London.

6. Rostow WW (1971) Politics and the stages of growth. Cambridge University Press, New York.

7. Lander E (1992) La ciencia y la tecnología como asuntos políticos. Límites de la democracia en la sociedad tecnológica, Caracas, de la Facultad de Ciencias Economicas y Sociales de la Universidad Central de Venezuela (FACES).

8. Heudebert GR (2017) The Privilege of being a physician and the immutable values of the medical profession. Trans Am Clin Climatol Assoc 128: 234-242.

9. Gouda HN, Powles JW (2014) The science of epidemiology and the methods needed for public health assessments: A review of epidemiology textbooks. BMC Public Health 14: 139.

10. Manrique EL (2017) On the meaning and usefulness of history of medicine (1895-1970). Rev chil Infectol: 34.

11. Jaramillo-Antillón J (2001) Evolución de la medicina: Pasado, presente y futuro. Acta méd costarric 43.

12. Jones WHS (1945) Hippocrates and the corpus hippocraticum. London Press, London.

13. Dubos RJ (1959) Mirage of health. Utopias, progress and biological change. New York, Harper.

14. Vega-Franco L (2002) Ideas, creencias y percepciones acerca de la salud. Reseña histórica. Salud Publica Mex 44: 258.

15. Foucault M (1996) El nacimiento de la clínica. Una arqueología de la mirada médica. Siglo XXI Editores, Mexico: 272.

16. Siebeck R (1957) Medicina en movimiento. Barcelona: Editorial Científico-Médica.

17. Buzzi AE (2014) Why is relevant the study of medicine history? Rev Argent Radiol 78: 118-119.

18. Roland CG (2003) Sir William Osler. Dictionary of Canadian biography. University of Toronto/Université Laval.

19. González Vélez M (2012) Sir William Osler. From the beginning of the university hospitals, to the satisfaction for modern medicine. CES Med: 26.

20. Maranon G (1976) Tiempo viejo y tiempo nuevo. Madrid: Espasa-Calpe, SA.

21. Spengler O (1947) El hombre y la técnica y otros ensayos. Buenos Aires: Espasa-Calpe, SA.

22. Cajal SRY (1944) Los tónicos de la voluntad. Buenos aires. Espasa-Calpe, SA.

23. Saad TC (2018) The history of autonomy in medicine from antiquity to principlism. Med Health Care Philos; 21: 125-137. 